\title{
Plasma miR-1273g-3p acts as a potential biomarker for early Breast Ductal Cancer diagnosis
}

\author{
HUAN GUO, XIANGTING ZENG, HAINING LI, YANXIANG GUO, TAO WANG, \\ HONGYUN GUO, GONGIIAN ZHU, LAN WANG, HAIHONG ZHOU, KEDAN LIU, \\ XIAOYI CHEN, HAITAO WANG, XINKE ZHAO, HAIXIANG SU \& YINGDONG LI
}

\begin{abstract}
Circulating miRNAs presenting in plasma in a stable manner have been demonstrated their potential role as a promising biomarkers in many human diseases, such as Alzheimer's disease, melanoma and ovarian carcinoma. However, few circulating miRNAs could be used for breast ductal cancer diagnosis. Here, we identified miR-1273g$3 p$ as a biomarker for detecting breast ductal cancer. We detected miR-1273g-3p levels in the plasma of 39 sporadic breast ductal cancer patients and 40 healthy donors by Stemloop Quantitative Real-time PCR (qRT-PCR). The results showed the plasma miR-1273g-3p level were significantly up-regulated in breast ductal cancer patients compared with healthy donors ( $p=0.0139)$. Receiver operating characteristic (ROC) curve also revealed the significantly diagnostic ability of miR-1273g-3p in patients ( $p=0.0414)$. In addition, the plasma level of miR-1273g-3p was closely related to IIIB-IIIC TNM stage. We also confirmed the higher expression level of miR-1273g-3p in breast cancer cell lines MCF-7 $(4.872 \pm 0.537)$ than normal breast cells (Hs 578Bst). Taken together, miR-1273g-3p could represent as a potential biomarker for early breast ductal cancer diagnosis.
\end{abstract}

Key words: breast ductal carcinoma, plasma, miR-1273g-3p, circulating miRNA, biomarker

\section{INTRODUCTION}

Breast cancer is the most frequently diagnosed cancer in any of the five continents (Bidoli et al. 2019). A higher frequency of early onset female breast cancer has been observed in low income countries than in high income countries (Bidoli et al. 2019), such as some Arab or Asian countries. Chinese Cancer Society estimated that the incidence and mortality of female breast cancer in china is increasing from 2000 to 2011, especially in women younger than 45 years (Chen et al. 2016). Furthermore, breast cancer is also the leading cause of death in women younger than 45 years (Chen et al. 2016).
The high mortality rate of breast cancer is due to rapid cancer cells proliferation and a great degree of malignancy, which has not been early detected and treated. Early detection of breast cancer can reduce the high mortality rate and improve treatment outcomes (Chatterjee and Zetter 2005). Conventional diagnostic method (including gold standard, mammography) is not adequately sensitive for early tumor detection (Torre et al. 2015, Bleyer \& Welch 2012, Weigelt et al. 2010, Kalinich \& Haber 2018). Therefore, finding new diagnostic methods, such as identification of plasma biomarkers of breast cancer could serve as non-invasive biomarkers to prolong patient survival. 
Currently, small non-coding RNAs (microRNAs) have opened a new avenue for early cancer diagnosis (Calin \& Croce 2006). MicroRNAs (miRNAs) are short, 18-24 nucleotide noncoding RNAs, which could regulate gene expression by binding to $3^{\prime}$-untranslated region (3'-UTR) of messenger RNAs (mRNAs) (Eulalio et al. 2008) and protein-coding exons regions (Forman et al. 2008, Hausser et al. 2009, Hendrickson et al. 2009) leading to the inhibition of mRNAs translation or mRNAs degradation. MiRNAs are involved in a broad range of biological processes including cell proliferation, development, apoptosis, and cancer progress as well (Hamam et al. 2017). Recent studies have reported that miRNAs were released into the blood circulation by various cell physiological events under both normal and pathological conditions (Chen et al. 2012). Compared with normal donors, the expression profiles of miRNAs in malignant tumors are different, and different stage of tumors have different expression profiles. The miRNAs that released into plasma or serum can be protected from endogenous RNase activity (Schwarzenbach 2017, Schwarzenbach et al. 2014). Moreover, plasma miRNA profiles of cancer with high sensitivity and specificity could reflect disease development, tumor load, malignant progression towards metastasis (Calin et al. 2004). Several studies have demonstrated that circulating miRNAs in plasma or serum are stable and detectable, and the levels of circulating miRNAs specifically elevated in the patients with lung cancer(Cho 2012), colorectal cancer (Yuan et al. 2017), gastric cancer, (Konishi et al. 2012) breast cancer (Hannafon et al. 2016, Cuk et al. 2013). Therefore, plasma miRNAs are promising biomarkers for the early and minimally invasive diagnosis of breast ductal cancer (Mitchell et al. 2008). The assessment of plasma miRNAs disregulation may serve as an additional tool for breast cancer detection following by mammography screening and core needle biopsy.

To date, several studies explored circulating miRNAs as breast cancer indicators (Li et al. 2018, Bertoli et al. 2015). However, the correlations between circulating miR-1273g-3p levels and breast cancer have not been identified. In this study, we detected that the plasma miR-1273g$3 p$ level were significantly up-regulated in breast ductal cancer patients compared with healthy donors $(p=0.0139)$. Receiver operating characteristic (ROC) curve also revealed the significantly diagnostic ability of miR-1273g-3p in patients $(p=0.0414)$. In addition, the plasma level of miR-1273g-3p was closely related to IIIB-IIIC TNM stage. We also confirmed the higher expression level of miR-1273g-3p in breast cancer cell lines MCF-7 (4.872 \pm 0.537$)$ than normal breast cells (Hs 578Bst). Taken together, miR-1273g-3p could represent as a promising candidate biomarker for early breast ductal cancer diagnosis.

\section{MATERIALS AND METHODS}

\section{Study population}

Blood samples were collected between 2015 and 2016 from patient at first clinic diagnosis from Gansu Province Cancer Hospital. All patients $(n=39)$ and healthy controls $(n=40)$ were Han women from Gansu province, China. All the patients had never got any surgery, radiation or systemic therapeutic procedures. For patients, the surgical resection tumor specimens were confirmed through histopathologic analysis and the tumor stage was determined according to the tumor-node-metastasis (TNM) system. Healthy control blood samples were collected from healthy women donors with no history of malignant diseases, no blood donations received in the previous 3 years and no current inflammatory condition. Patients' clinical 
outcomes were listed in Table I. This study was approved by the Ethical Committee (the certificate number: A201503180009, Date: 0318-2015) of Gansu Province Cancer Hospital in Lan Zhou, China. Written informed consent was obtained from all participants involved in this study.

\section{Plasma samples}

Blood samples were withdrawn in EDTA tubes and processed within 2 hours. Plasma were separated after twice centrifugation at $4^{\circ} \mathrm{C}$ (1000g for 10 minutes and $12000 \mathrm{~g}$ for 10 minutes) and stored at $-80^{\circ} \mathrm{C}$.

\section{RNA extraction}

Total RNA containing small RNA was extracted from $400 \mu$ l plasma using miRVana ${ }^{T M}$ RNA Isolation Kit AM1561(Invitrogen, ThermoFisher scientific, CA, USA) according to the manufacturer's instructions with a minor modification: $25 \mathrm{fmol}$ of a C. elegans miR-39 (Cel-miR-39) was spikedin of validation participants and eluted with 30 $\mu \mathrm{l}$ of nuclease free water. The concentration of all RNA samples were quantified by NanoDrop ND-2000 (Thermo scientific, CA, USA).

\section{MiRNA quantification}

Stem-loop Quantitative Real-time PCR (qRTP(R) assay was used for miRNAs validation. In brief, miRNAs were transcribed to CDNA using the SuperScript ${ }^{T M}$ III Reverse Transcriptase kit (Invitrogen, ThermoFisher scientific, CA, USA) and Bulge-loop ${ }^{T M}$ miRNA RT primer (Bulgeloop ${ }^{\mathrm{TM}}$ miRNA qRT-PCR Primer Sets: one specific RT primer and a pair of qPCR primers for each set) specific for miRNA purchased from RiboBio (Guangzhou RiboBio Co., Guangzhou, China). Then, qRT-PCR was performed on Quantstudio ${ }^{T M}$ 12k Flex Real-Time PCR system (Applied Biosystems, ThermoFisher scientific, CA, USA). The reaction was performed at $95^{\circ} \mathrm{C}$ for $2 \mathrm{~min}$, followed by 40 cycles at $95^{\circ} \mathrm{C}$ for $15 \mathrm{~s}, 60{ }^{\circ} \mathrm{C}$ for $30 \mathrm{~s}$ and $72{ }^{\circ} \mathrm{C} 15 \mathrm{~s}$, and then ramped from $65^{\circ} \mathrm{C}$ to $95^{\circ} \mathrm{C}$ to obtain the melting curve. Each sample was run in duplicates for analysis. The relative expression level of miRNA was normalized to Cel-miR-39, and fold change of miRNA was calculated by the $2^{-\Delta \Delta c t}$ method.

\section{Target prediction}

The potential target genes of miR-1273g-3p were predicted by PicTar (http://pictar.mdc-berlin. de/cgi-bin/PicTar_vertebrate.cgi), TargetScan7.1 (http://www.targetscan.org/) and microTCDS (http://www.microrna.gr/microT-CDS). Considering that the predictn programs often suffer from high false positive rates, only the target genes predicted by both tools were taken into account.

\section{Gene ontology (GO) term analysis of target genes}

In order to infer the potential functions of the differentially expressed miRNAs, the functional analysis of their target genes was analyzed by Shanghai OE Biotech Technology Co, Ltd. (Shanghai, China). Functional categories were clustered using the Functional Annotation Clustering tool, and representative $\mathrm{GO}$ categories and KEGG pathways from each clustered set with a $p$-value $<0.05$ were selected and taken into consideration for further analysis.

\section{Cell culture}

Cell lines were purchased from ATCC. Hs 578Bst is breast normal cell. MDA-MB-231, MCF-7, T47-D, ZR-75-1 are breast cancer cell. Hs 578Bst and MDA-MB-231 were cultured in RPMI complete medium (RPMI/10\% FCS/1\% Sodium pyruvate/2mM L-glutamine/PenStrep). MCF-7, T47-D, ZR-75-1 were grown in DMEM complete medium (DMEM/10\% FCS/2mM L-glutamine/ 
Table I. Clinical characteristics of the healthy volunteers, breast ductal cancer patients and pathological characteristics of breast ductal cancers in the discovery and validation cohorts.

\begin{tabular}{|c|c|c|c|}
\hline Clinicopathologic features & Cases n (\%) & Healthy Controls & $p$-value \\
\hline $\begin{array}{l}\text { Number of patients } \\
\text { Age }(\text { mean } \pm \text { SD) } \\
\text { Tumor size }(\mathrm{cm})^{c}\end{array}$ & $\begin{array}{c}39 \\
49.91 \pm 9.795\end{array}$ & $\begin{array}{c}40 \\
49.23 \pm 8.529\end{array}$ & 0.7369 \\
\hline$\leq 2 \mathrm{~cm}$ & $9(23.08)$ & & \\
\hline$>2 \mathrm{~cm}$ & $30(76.92)$ & & \\
\hline \multicolumn{4}{|l|}{ TNM stage } \\
\hline$|-| \mid a$ & $13(33.33)$ & & \\
\hline$\| \mathrm{lb}-|| \mid \mathrm{a}$ & $20(51.28)$ & & \\
\hline$\|I I b-I\| c$ & $6(15.39)$ & & \\
\hline \multicolumn{4}{|l|}{ ER status } \\
\hline Negative & 13(33.33) & & \\
\hline Positive & $26(66.67)$ & & \\
\hline \multicolumn{4}{|l|}{ PR status } \\
\hline Negative & $21(53.85)$ & & \\
\hline Positive & $18(46.15)$ & & \\
\hline \multicolumn{4}{|l|}{ Her-2 } \\
\hline Negative & $31(79.49)$ & & \\
\hline Positive & $8(20.51)$ & & \\
\hline \multicolumn{4}{|l|}{ Ki67 } \\
\hline$<14 \%$ & $8(20.51)$ & & \\
\hline$>14 \%$ & $31(79.49)$ & & \\
\hline \multicolumn{4}{|l|}{ P53 } \\
\hline Negative & $21(53.85)$ & & \\
\hline Positive & $18(46.15)$ & & \\
\hline \multicolumn{4}{|l|}{ Lymph node metastasis } \\
\hline Negative & $20(51.28)$ & & \\
\hline Positive & $19(48.72)$ & & \\
\hline
\end{tabular}

PenStrep). Cells were maintained in an incubator with $5 \% \mathrm{CO}_{2}, 21 \% \mathrm{O}_{2}$ at $37^{\circ} \mathrm{C}$.

\section{Statistical Analysis}

All statistical calculations were performed by GraphPad PRISM 7 software (GraphPad Software, (A, USA). The significance of plasma miRNA levels was determined by Mann-Whitney test, $x^{2}$-test or Kruskal-Wallis test where appropriate. ROC curve were established for determine the diagnostic value of miRNAs. All $p$-values are two-tailed and less than 0.05 was considered to be statistically significant.

\section{RESULTS}

\section{Clinical characteristics of patients}

The clinical characteristics and the pathology of the breast ductal cancer patients were summarized in Table I. Plasma samples from 39 patients and 40 healthy controls were used for this study. There were no significant differences in age between patients and healthy controls ( $49.91 \pm 9.795$ vs $49.23 \pm 8.529, p=0.7369)$. All cases were histologically confirmed as ductal carcinoma of the breast with a tumor size ranging from 0.15 to $4.0 \mathrm{~cm}$. Of the 39 patients 
with tumor $\leq 2 \mathrm{~cm}$ were $23.08 \%(\mathrm{n}=9)$ and tumor $>2 \mathrm{~cm}$ were $76.92 \%(\mathrm{n}=30)$. For TNM stage in 39 patients, 33.33\% were TNM stage I-IIa $(n=13)$, 51.28\% TNM stage IIb-IIIa $(n=20)$ and 15.39\% TNM stage IIIb-IIIc ( $n=6) .13$ patients were ER-negative (33.33\%) and 26 patients were ER-positive (66.67\%). 21 patients were PR-negative (53.85\%) and 18 patients were PR-positive (46.18\%). 31 patients were Her2-negative (79.49\%) and 8 patients were Her2-positive (20.51\%). 8 patients were Ki67-negative (20.51\%) and 31 patients were Ki67-positive (79.49\%). 21 patients were P53-negative (53.85\%) and 18 patients were P53positive (46.15\%). 20 patients were lymph node metastasis-negative (51.28\%) and 19 patients were lymph node metastasis-negative-positive (48.72\%).

\section{Validation of miRNAs in Breast Ductal Cancer plasma}

To identify the miRNAs candidates as biomarker in breast ductal cancer plasma, plasma levels of miR-21-5p and miR-1273g-3p were measured by Stem-loop qRT-PCR assays. The results showed that miR-21-5p ( $p=0.0043)$ and miR-1273g-3p $(p=0.0139)$ in the plasma of patients had higher expression than healthy control (Fig. 1a).

\section{Evaluate the diagnostic value for miRNAs}

To further verify the discriminating power of two miRNAs for breast ductal cancer diagnosis, receiver operating characteristic (ROC) curve analysis was performed. The area under cure (AUC) closer to 1 reflected more substantial differences between breast cancer and healthy

a

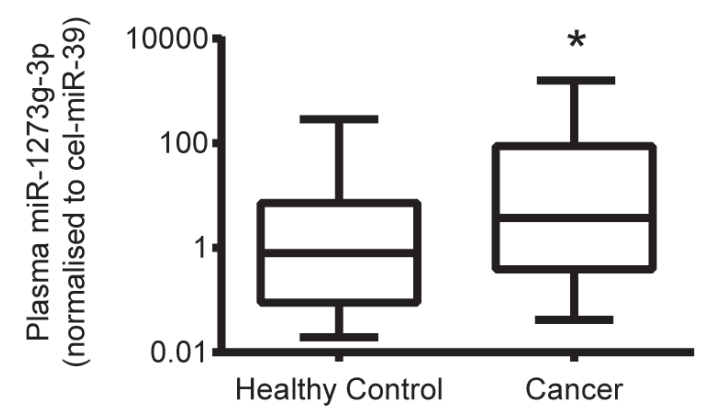

b

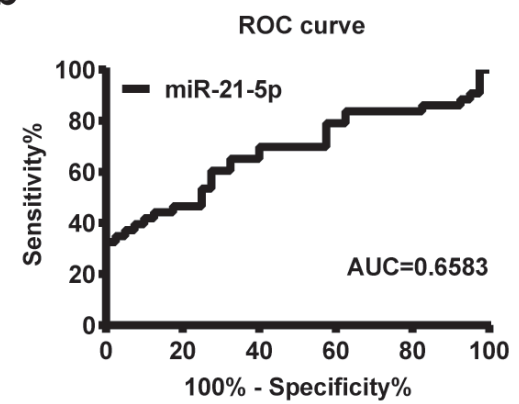

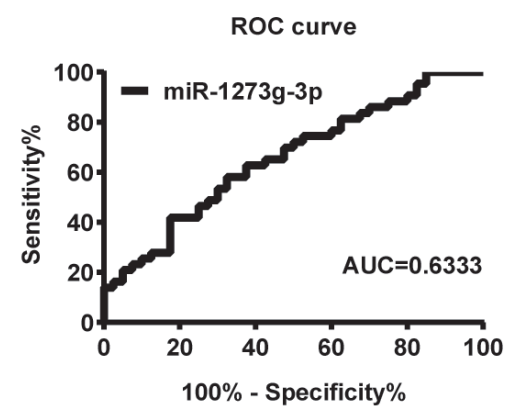
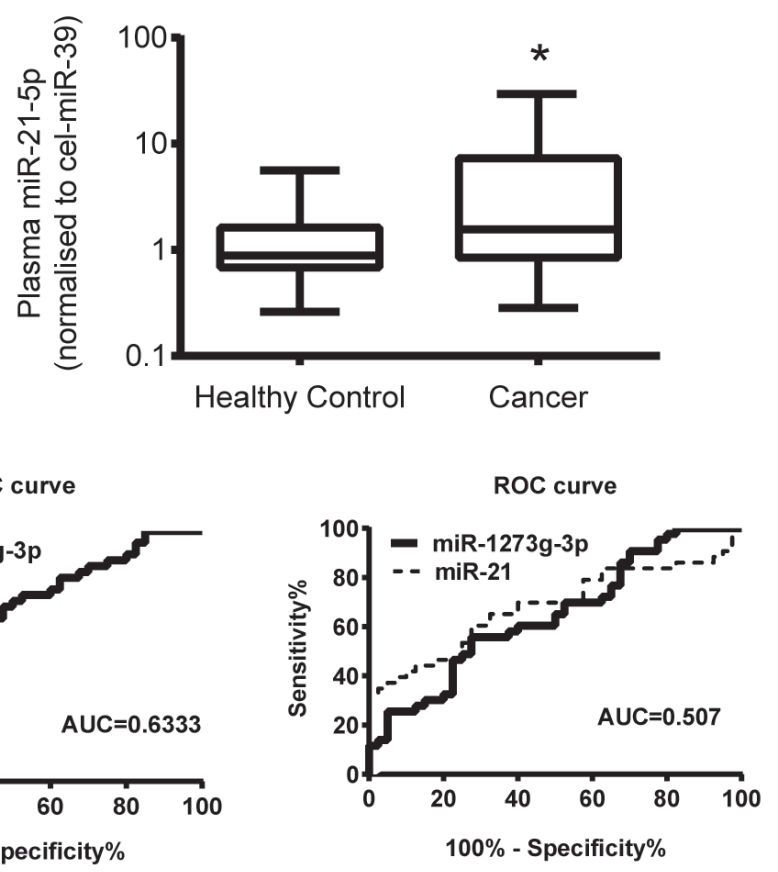

Figure 1. Validation of miRNAs in breast ductal cancer and healthy controls $(n=79)$. (a) Box plot of plasma levels of miR-21-5p and miR-1273g-3p in breast cancer ductal patients. The expression of miRNAs was normalised to cel-miR-39. The lines inside the boxes represent the medians. The boxes mark the interval between the 25th and 75th percentiles. The whiskers denote the interval between the 10th and 90th percentiles. Statistically significant differences were determined using Mann-Whitney tests. (b) Receiver-operator characteristics (ROC) curve analysis of miRNAs to discriminate BC patients from healthy controls. ${ }^{*} p<0.05$. 
control. ROC analysis of miR-21-5p (AUC $=0.6583$, 95\% Cl: $0.5345-0.7822, p=0.0154)$ and $\mathrm{miR}-1273 \mathrm{~g}-$ $3 p(A \cup C=0.6333,95 \% \mathrm{Cl}: 0.5114-0.7552, p=0.0414)$ were shown in Fig. 1b. Although miR-21-5p and miR-1273g-3p alone generated satisfactory ROC values, the AUC value was not elevated when the two miRNAs were combined (Fig. 1b).

\section{The relationship between plasma miRNAs levels and clinical features}

To determine if two plasma miRNAs level were associated with clinical features, patients were stratified (Table II). We found there were no differences of two miRNA levels among tumor size, ER status, PR status, Her2 status, Ki67, P53 and Lymph node metastasis. The plasma levels of miR-21-5p, miR-1273g-3p in breast ductal cancer patients at different TNM stages were also evaluated to determine if the plasma miRNAs could be detected in breast ductal cancer (Fig. 2a). Patients with high miR21-5p expression were associated with high risk of breast malignancy compared to those with low miR-21-5p expression profiles (Stage IIbIIIa vs healthy control, $p=0.0012$; Stage IIIb- IIIC vs healthy control, $p=0.0168$, stage IIb-IIIa vs

Table II. Correlation of the expression of plasma miRNA with clinicopathologic features.

\begin{tabular}{|c|c|c|c|c|}
\hline Clinicopathologic features & $\begin{array}{c}\text { Relative expression of } \\
\text { miR-21-5 } p^{\mathrm{a}}\end{array}$ & $p$-value & $\begin{array}{l}\text { Relative expression } \\
\text { of miR- } 1273 g-3 p^{\mathrm{a}}\end{array}$ & $p$-value ${ }^{\mathrm{b}}$ \\
\hline Tumor size $(\mathrm{cm})^{c}$ & & 0.5660 & & 0.8829 \\
\hline$\leq 2 \mathrm{~cm}$ & $1.564(0.9175-5.742)$ & & $5.236(0.1916-241)$ & \\
\hline$>2 \mathrm{~cm}$ & $1.465(0.7072-8.103)$ & & $3.159(0.3694-64.21)$ & \\
\hline \multicolumn{5}{|l|}{ TNM stage } \\
\hline$|-| \mid a$ & $0.8423(0.3855-2.035)$ & 0.0188 & $0.9511(0.241-4.112)$ & 0.1212 \\
\hline||$b-|| \mid a$ & $1.823(1.237-10.110)$ & & $4.488(0.4059-80.34)$ & \\
\hline$\| I|b-I I| c$ & $7.519(0.9565-23.13)$ & & $113.3(2.538-837.0)$ & \\
\hline ER status & & 0.9883 & & 0.8716 \\
\hline Negative & $1.518(0.3855-12.5200)$ & & $3.368(0.1242-466)$ & \\
\hline Positive & $1.502(0.8433-5.318)$ & & $3.246(0.6003-17.52)$ & \\
\hline PR status & & 0.4944 & & 0.6061 \\
\hline Negative & $0.4944(0.6144-6.4990)$ & & $2.949(0.241-34.03)$ & \\
\hline Positive & $1.823(0.8433-7.72)$ & & $5.5(0.3694-99.77)$ & \\
\hline Her-2 & & 0.2087 & & 0.1728 \\
\hline Negative & $1.564(0.8445-6.59)$ & & $3.74(0.7432-56.15)$ & \\
\hline Positive & $0.737(0.3098-10.34)$ & & $0.4186(0.07582-255)$ & \\
\hline Ki67 & & 0.5730 & & 0.3283 \\
\hline$<14 \%$ & $3.267(0.9761-6.972)$ & & 9.415(1.689-108.9) & \\
\hline$>14 \%$ & $1.412(0.8423-5.899)$ & & $1.718(0.3163-56.15)$ & \\
\hline P53 & & 0.7487 & & 0.1925 \\
\hline Negative & $1.412(0.8327-5.397)$ & & $1.269(0.2169-34.1)$ & \\
\hline Positive & $1.541(0.7439-12.2)$ & & $7.119(0.9798-120)$ & \\
\hline Lymph node metastasis & & 0.3653 & & $>0.9999$ \\
\hline Negative & $1.406(0.8426-4.297)$ & & $3.456(0.4579-45.13)$ & \\
\hline Positive & $2.295(0.7801-11.11)$ & & $2.949(0.1657-88.4)$ & \\
\hline
\end{tabular}

${ }^{a}$ Median of relative expression, with 25 th-75th percentile in parentheses. ${ }^{b} p<0.05$ was considered significant (Mann-Whitney U test between 2 groups and Kruskall-Wallis test for 3 groups).'Maximal tumor diameter. 
a

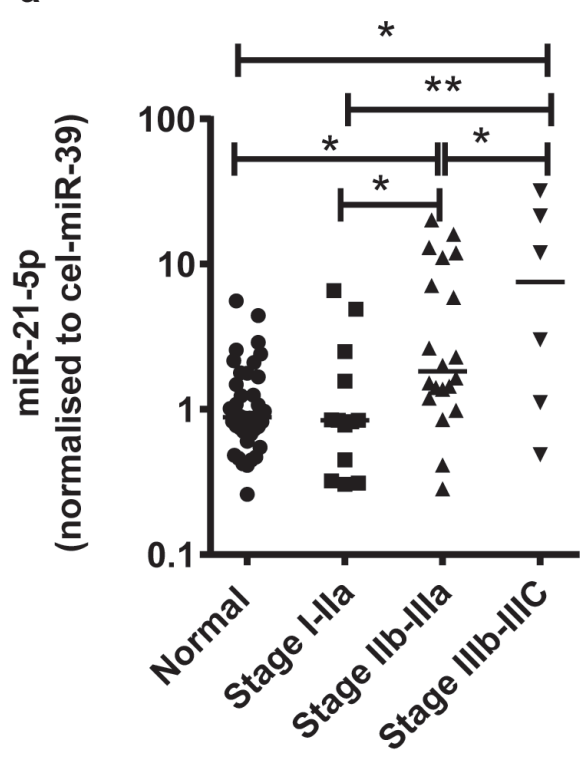

b

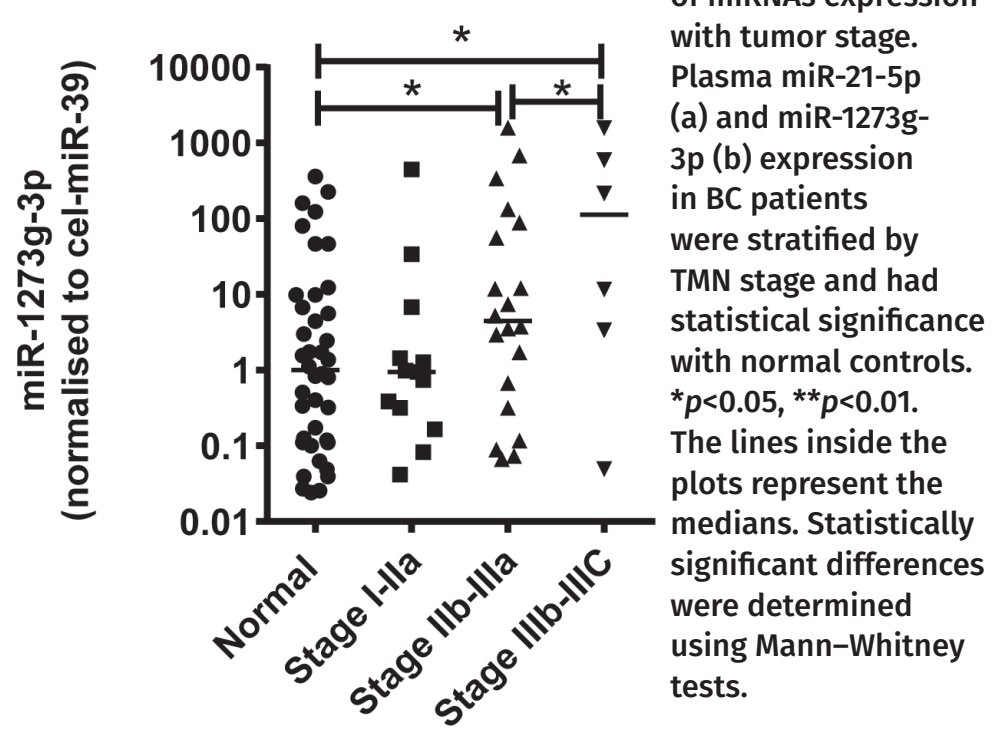

stage I- Ila, $p=0.0127$, stage $\|$ Ib- IIIc vs stage I- IIa, $p=0.0365$ ). While compared stage I-Ila patient with healthy control, miR-21-5p expression showed no significant difference $(p=0.5741)$. The plasma miR-1273g-3p showed marked difference when stage IIIb-IIIc compare with healthy control $(p=0.0392)$ (Fig. 2b).

\section{Gene ontology (GO) term analysis of miR- 1273g-3p}

To address how functions and pathways could be affected by the complex interactions between the miRNAs and their target genes, we inferred the functions of miRNAs from their target genes. The functional analysis showed that miR-1273g-3p target genes were involved in a variety of positive regulation processes, such as protein complex assembly, phosphatidylinositol-mediated signaling, regulation of gene expression, Wnt signaling pathway, regulation of transcription and DNA-templated (Fig. 3a). Further analysis found that the target genes of miR-1273g-3p were enriched in the pathways related to cancer, Hippo signaling pathway (Fig. 3b). These results indicate that miR-1273g-3p may play a key role in carcinogenesis by regulating various biological

processes. For detailed functional analysis of the miRNA in breast ductal cancer will be studied in the future.

\section{Cell expression of miR-1273g-3p}

To test the level of miR-1273g-3p expression, we examined the miRNA expression in MCF-7, T47-D, ZR-75-1 and MDA-MB-231 cells. The results revealed relative high expression of miR-1273g-3p in MCF-7 (4.872 \pm 0.537$)$ and in ZR-75-1 (1.551 \pm 0.410$)$ cell, but low expression in T47-D $(0.678 \pm 0.166)$ and in MDA-MB-231 $(0.835 \pm 0.417)$ when compare with Hs 578Bst breast normal cell (Fig. 4).

\section{DISCUSSION}

According to the data from American Cancer Society, an estimated 252,710 cases of invasive breast cancer and an additional 63,420 new cases of in situ lesions of the breast were diagnosed in 2017, furthermore among them 40,610 patients would die from breast cancer (Siegel et al. 2017). In most cases, breast cancer is diagnosed after the symptoms, but in many cases the disease is already in advanced clinical stage when symptoms occur. Thus, early diagnosis plays a 
very important role to improve the survival rate and life quality for breast cancer patients. When early stage of cancer, there are many biological changes appearing in the body, some genes are over-expressed, while others are underexpressed. Therefore, identifying differentially expressed genes as an effective biological marker, which, the expression of these genes is stable and reliable, for early diagnosis of cancer is a promising direction for current cancer research.

MiRNAS is a class of small non-coding RNAs containing 22 nucleotides, which generally negatively regulate gene expression at the posttranscription stage. Recent studies revealed that miRNAs could have effect on cancer related processes, such as cell proliferation, differentiation and apoptosis(Jansson and Lund 2012). Consequently, many researchers using circulating miRNAs as cancer biomarkers are being carried out widely. In recent years, there is a great deal of studies demonstrated the genetic association between miRNAs and cancer, including lung cancer ( $\mathrm{Hu}$ et al. 2016) colorectal cancer (Schetter and Harris 2009) and breast cancer(Takahashi et al. 2015, Kurozumi et al. 2017). Several previous studies have demonstrated the value of plasma/serum miRNA in breast cancer diagnosis (Lagendijk et al. 2018, Khodadadi-Jamayran et al. 2018, Li et al. 2017, Souza et al. 2019). MiR-21 is involved in regulating the expression of multiple tumor suppressor genes, and plays a crucial role in the occurrence and development of a variety of diseases (Folini et al. 2010, Peralta-Zaragoza et al. 2016). Matamala et al. (2015) reported that miR-21 had significantly higher expression in circulating of breast carcinoma patients compared to healthy donors. A plurality of studies have shown that up-regulation of miR21 was detected in blood (Alunni-Fabbroni et al. 2018), and that plasma miR-21 could be used as a non-invasive biomarker for breast cancer diagnosis, as well as an indicator for tumor invasiveness (Hannafon et al. 2016). Our results were consist with previous study. Therefore, miR21 is a promising biomarker for breast cancer diagnosis in clinics. However, breast cancer is a very complicated disease according to their clinical characteristics. Identifying new miRNAs as biomarkers are urgent need for breast cancer diagnosis. In our study, we found miR-1273g-3p is an important regulator in breast cancer cell proliferation (data not shown), and we also focus on the capacity of miR-1273g-3p as biomarker.

Currently, little is known about the functional role of miR-1273g-3p in breast cancer. MiR-1273g-3p located on chromosome 1 at 1p32.3, is a member of the miR-1273 family. MiR-1273 consists of miR-1273a, miR-1273c, miR-1273d, miR1273e, miR-1273f, miR-1273g-3p, miR-1273g-5p, miR-1273h-3p and miR-1273h-5p (Ivashchenko et al. 2014). Guo and his colleagues found that miR-1273g-3p participates in acute glucose fluctuation-induced autophagy, dysfunction, and proliferation attenuation in human umbilical vein endothelial cells (Guo et al. 2016). Sahu and his colleagues found that miR-1273g-3p had a relationship with megakaryocyte differentiation (Sahu et al. 2018). Niu et al. (2016) found that miR-1273g-3p was the most significantly upregulated miRNA and correlated with the stage of HCV-related liver fibrosis. Fang et.al using next generation sequencing technology detected that miRNA1273g/miRNA382 was up regulated in breast cancer plasma (Fang et al. 2018).

In this study, we identify miR-1273g-3p and miR-21-5p as a potential biomarker for breast cancer diagnosis by Stem-loop Quantitative Real-time PCR (qRT-PCR). Our results also confirmed the plasma miR-1273g-3p level were significantly up-regulated in breast ductal cancer patients compared with healthy donors $(p=0.0139)$. However, miR-21-5p has been 
confirmed as a robust biomarker by many groups. It suggested that miR-1273g-3p has the same ability as miR-21-5p to distinct breast cancer from healthy person. Therefore, miR$1273 \mathrm{~g}-3 \mathrm{p}$ could be a very promising candidate for breast ductal cancer diagnosis. However, the detection efficiency of breast cancer was not enhanced when we combined the two miRNAs into diagnostic panles.

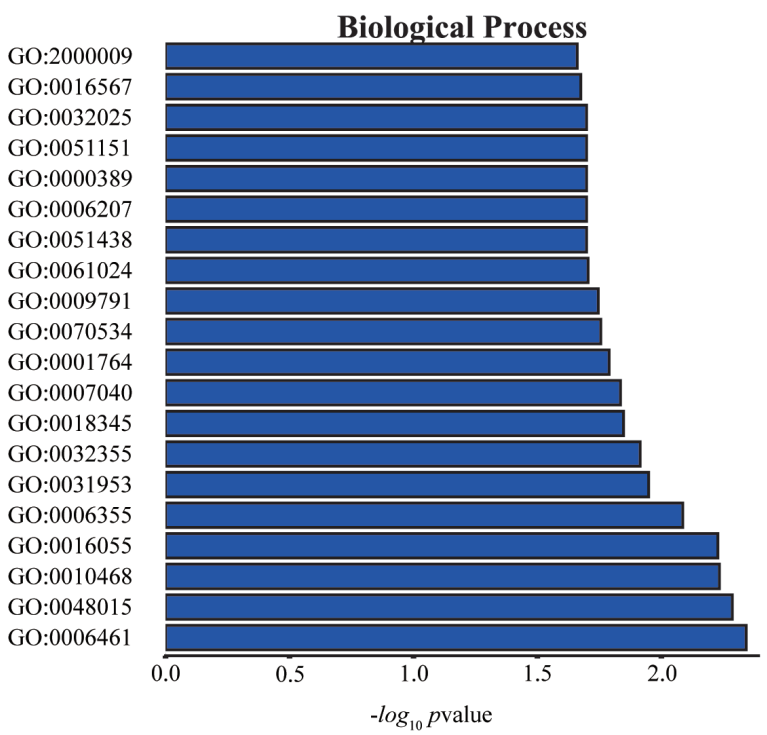

Some researchers found that hsa-miR$1273 g-3 p$ regulates several significant genes (Niu et al. 2016, Gao et al. 2019). Phosphatase and tensin homolog deleted on chromosome ten (PTEN) was known as a tumor suppressor gene and are low expressed in hepatocellular cancer(Qian et al. 2017), gastric cancer (Zhang et al. 2017), and breast cancer (Gao et al. 2019). Over-expression of miR-1273g-3p could inhibit translation of PTEN, increase the expression of

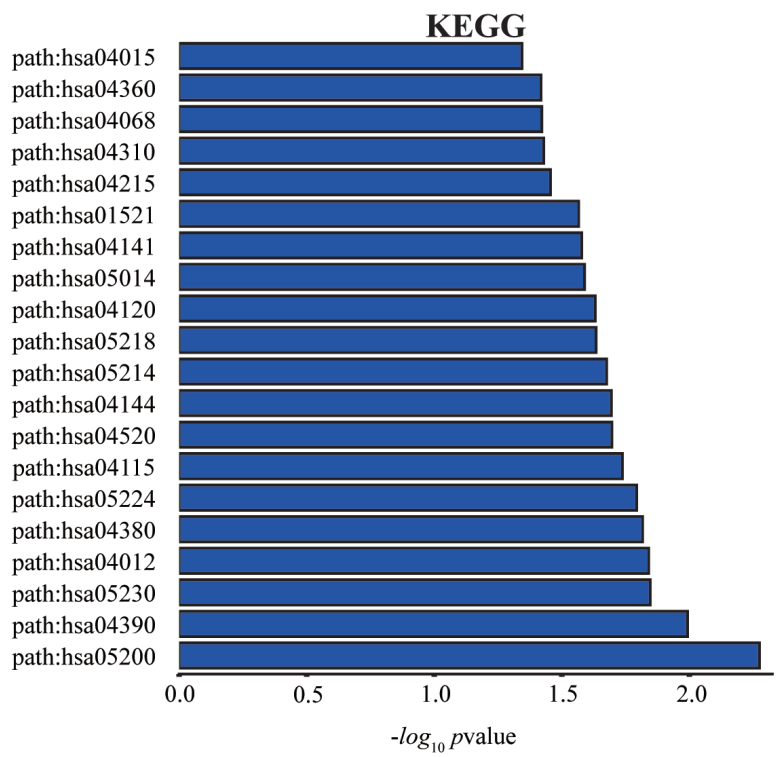

Figure 3. Biological Process GO terms (a) and KEGG pathways (b) enriched in the target genes of miR-1273g-3p.

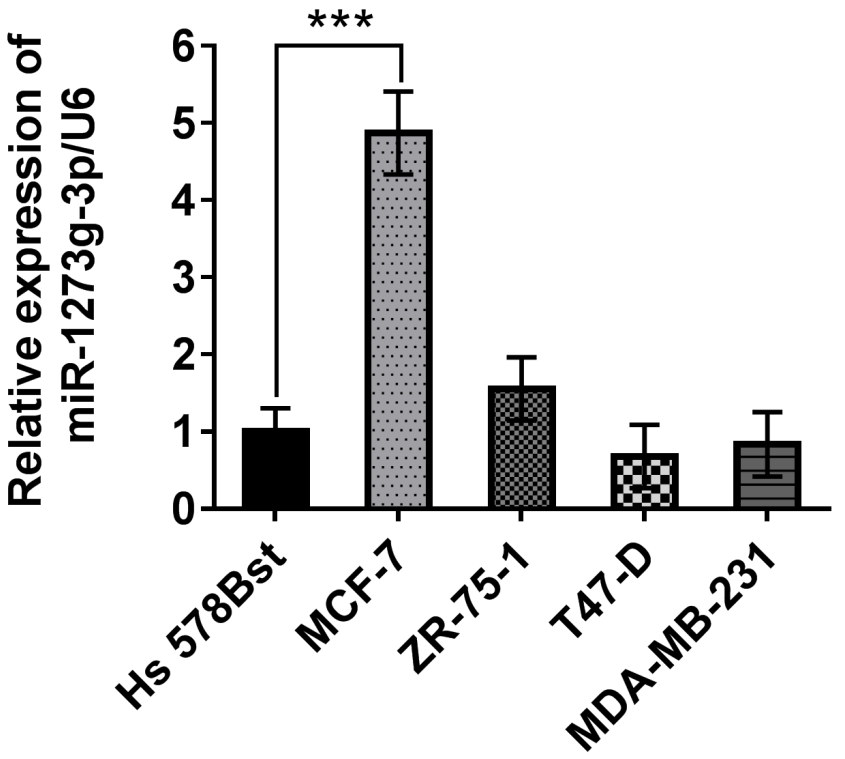

Figure 4. Relative Expression of miR-1273g-3p in breast cancer cell lines.** $p<0.001$. 
a-SMA, Col1A1, and reduce apoptosis in HSCs. As PTEN can modulated tumor progression via PI3K/ AKT pathway is tightly correlated with breast cancer aggressiveness, stage and prognosis (Gao et al. 2019). Here, we make a preliminary infer that hsa-miR-1273g-3p maybe have effect on tumorigenesis and progress of breast cancer by regulating the expression of PTEN.(Figure S1 Supplementary Material).

In conclusion, we demonstrated that miR$1273 g-3 p$ is over-expressed and may contribute to promoting progression of breast cancer, the miR-1273g-3p may have potential utility as both prognostic and diagnostic biomarker.

\section{Acknowledgments}

This study was supported by a grant from Scientific Research Project of Health and Family Planning Commission of Gansu Province, China (Grant No.GSWSKY-2015-25). This research was supported by the Natural Science Foundation for Young Scientists through Gansu provincial Science and Technology Department, China (Grant No.17JR5RA042\& No.1606RJYA296). This research was supported by Gansu science and technology program (Grant No.17JR3TA013) through Gansu provincial Science and Technology Department, China. The authors thank the patients and the healthy donors who participated in this study.

\section{REFERENCES}

ALUNNI-FABBRONI M ET AL. 2018. Whole blood microRNAs as potential biomarkers in post-operative early breast cancer patients. BMC Cancer 18: 141.

BERTOLI G, CAVA C \& CASTIGLIONI I. 2015. MicroRNAS: New Biomarkers for Diagnosis, Prognosis, Therapy Prediction and Therapeutic Tools for Breast Cancer. Theranostics 5: 1122-1143.

BIDOLI E, VIRDONE S, HAMDI-CHERIF M, TOFFOLUTTI F, TABORELLI M, PANATO C \& SERRAINO D. 2019. Worldwide Age at Onset of Female Breast Cancer: A 25-Year Population-Based Cancer Registry Study. Sci Rep 9: 14111.

BLEYER A \& WELCH HG. 2012. Effect of three decades of screening mammography on breast-cancer incidence. $\mathrm{N}$ Engl J Med 367: 1998-2005.
CALIN GA \& CROCE CM. 2006. MicroRNA signatures in human cancers. Nat Rev Cancer 6: 857.

CALIN GA ET AL. 2004. Human microRNA genes are frequently located at fragile sites and genomic regions involved in cancers. Proc Natl Acad Sci USA 101: 2999-3004.

CHATTERJEE SK \& ZETTER BR. 2005. Cancer biomarkers: knowing the present and predicting the future. Future Oncol 1: 37-50.

CHEN W, ZHENG R, BAADE PD, ZHANG S, ZENG H, BRAY F, JEMAL A, YU XQ \& HE J. 2016. Cancer statistics in China, 2015. CA Cancer J Clin 66: 115-132.

CHEN X, LIANG H, ZHANG J, ZEN K \& ZHANG CY. 2012. Secreted microRNAs: a new form of intercellular communication. Trends Cell Biol 22: 125-132.

CHO WC. 2012. [Promises and challenges in developing MiRNA as a molecular diagnostic tool for lung cancer]. Zhongguo fei ai za zhi = Chinese Journal of Lung Cancer 15: C1-3.

CUK K ET AL. 2013. Circulating microRNAs in plasma as early detection markers for breast cancer. Int I Cancer 132: 1602-1612.

EULALIO A, HUNTZINGER E \& IZAURRALDE E. 2008. Getting to the root of miRNA-mediated gene silencing. Cell 132: 9-14.

FANG R, ZHU Y, HU L, KHADKA VS, AI J, ZOU H, JU D, JIANG B, DENG Y \& HU X. 2018. Plasma MicroRNA Pair Panels as Novel Biomarkers for Detection of Early Stage Breast Cancer. Front Physiol 9: 1879.

FOLINI M ET AL. 2010. miR-21: an oncomir on strike in prostate cancer. Mol Cancer 9: 12.

FORMAN JJ, LEGESSE-MILLER A \& COLLER HA. 2008. A search for conserved sequences in coding regions reveals that the let-7 microRNA targets Dicer within its coding sequence. Proc Natl Acad Sci USA 105: 14879-14884.

GAO X, QIN T, MAO J, ZHANG J, FAN S, LU Y, SUN Z, ZHANG Q, SONG B \& LI L. 2019. PTENP1/miR-20a/PTEN axis contributes to breast cancer progression by regulating PTEN via PI3K/ AKT pathway. J Exp Clin Cancer Res 38: 256.

GUO J, SANG Y, YIN T, WANG B, YANG W, LI X, LI H \& KANG Y. 2016. miR-1273g-3p participates in acute glucose fluctuationinduced autophagy, dysfunction, and proliferation attenuation in human umbilical vein endothelial cells. Am J Physiol Endocrinol Metab 310: E734-743.

HAMAM R, HAMAM D, ALSALEH KA, KASSEM M, ZAHER W, ALFAYEZ M, ALDAHMASH A \& ALAJEZ NM. 2017. Circulating microRNAS in breast cancer: novel diagnostic and prognostic biomarkers. Cell Death Dis 8: e3045. 
HANNAFON BN, TRIGOSO YD, CALLOWAY CL, ZHAO YD, LUM DH, WELM AL, ZHAO ZJ, BLICK KE, DOOLEY WC \& DING WQ. 2016. Plasma exosome microRNAs are indicative of breast cancer. Brest Cancer Res: BCR 18: 90.

HAUSSER J, LANDTHALER M, JASKIEWICZ L, GAIDATZIS D \& ZAVOLAN M. 2009. Relative contribution of sequence and structure features to the mRNA binding of Argonaute/ EIF2C-miRNA complexes and the degradation of miRNA targets. Genome Res 19: 2009-2020.

HENDRICKSON DG, HOGAN DJ, MCCULLOUGH HL, MYERS JW, HERSCHLAG D, FERRELL JE \& BROWN PO. 2009. Concordant regulation of translation and $m$ RNA abundance for hundreds of targets of a human microRNA. PLoS Biology 7: e1000238.

HU L, AI J, LONG H, LIU W, WANG X, ZUO Y, LI Y, WU Q \& DENG Y. 2016. Integrative microRNA and gene profiling data analysis reveals novel biomarkers and mechanisms for lung cancer. Oncotarget 7: 8441-8454.

IVASHCHENKO A, BERILLO O, PYRKOVA A \& NIYAZOVA R. 2014. Binding sites of miR-1273 family on the mRNA of target genes. Biomed Res Int 2014: 620530.

JANSSON MD \& LUND AH. 2012. MicroRNA and cancer. Mol Oncol 6: 590-610.

KALINICH M \& HABER DA. 2018. Cancer detection: Seeking signals in blood. Science 359: 866-867.

KHODADADI-JAMAYRAN A ET AL. 2018. Prognostic role of elevated mir-24-3p in breast cancer and its association with the metastatic process. Oncotarget 9: 12868-12878.

KONISHI H ET AL. 2012. Detection of gastric cancerassociated microRNAs on microRNA microarray comparing pre- and post-operative plasma. $\mathrm{Br}$ J Cancer 106: 740-747.

KUROZUMI S, YAMAGUCHI Y, KUROSUMI M, OHIRA M, MATSUMOTO H \& HORIGUCHI J. 2017. Recent trends in microRNA research into breast cancer with particular focus on the associations between microRNAs and intrinsic subtypes. J Hum Genet 62: 15-24.

LAGENDIJK M, SADAATMAND S, KOPPERT LB, TILANUS-LINTHORST MMA, DE WEERD V, RAMIREZ-MORENO R, SMID M, SIEUWERTS AM \& MARTENS JWM. 2018. MicroRNA expression in pretreatment plasma of patients with benign breast diseases and breast cancer. Oncotarget 9: 24335-24346.

LI HYET AL. 2017. miR-105/93-3p promotes chemoresistance and circulating miR-105/93-3p acts as a diagnostic biomarker for triple negative breast cancer. Brest Cancer Res: BCR 19: 133.
LI M, ZHOU Y, XIA T, ZHOU X, HUANG Z, ZHANG H, ZHU W, DING $\mathrm{Q} \&$ \& WANG S. 2018. Circulating microRNAs from the miR106a-363 cluster on chromosome $X$ as novel diagnostic biomarkers for breast cancer. Breast Cancer Res Treat 170: 257-270.

MATAMALA N ET AL. 2015. Tumor microRNA expression profiling identifies circulating microRNAs for early breast cancer detection. Clin Chem 61: 1098-1106.

MITCHELL PS ET AL. 2008. Circulating microRNAs as s bloodbased markers for cancer detection. Proc Natl Acad Sci USA 105: 10513-10518.

NIU X ET AL. 2016. miR-1273g-3p modulates activation and apoptosis of hepatic stellate cells by directly targeting PTEN in HCV-related liver fibrosis. FEBS Lett 590: 2709-2724.

PERALTA-ZARAGOZA O ET AL. 2016. Relevance of miR-21 in regulation of tumor suppressor gene PTEN in human cervical cancer cells. BMC Cancer 16: 215.

QIAN YY, LI K, LIU QY \& LIU ZS. 2017. Long non-coding RNA PTENP1 interacts with miR-193a-3p to suppress cell migration and invasion through the PTEN pathway in hepatocellular carcinoma. Oncotarget 8: 107859-107869.

SAHU I, HEBALKAR R, KAR S, TS S, GUTTI U \& GUTTI RK. 2018. Systems biology approach to study the role of miRNA in promoter targeting during megakaryopoiesis. Exp Cell Res 366: 192-198.

SCHETTER AJ \& HARRIS CC. 2009. Plasma microRNAs: a potential biomarker for colorectal cancer? Gut 58: 1318-1319.

SCHWARZENBACH H. 2017. Clinical Relevance of Circulating, Cell-Free and Exosomal microRNAs in Plasma and Serum of Breast Cancer Patients. Oncol Res Treat 40: 423-429.

SCHWARZENBACH H, NISHIDA N, CALIN GA \& PANTEL K. 2014. Clinical relevance of circulating cell-free microRNAs in cancer. Nat Rev Clin Oncol 11: 145-156.

SIEGEL RL, MILLER KD \& JEMAL A. 2017. Cancer Statistics, 2017. CA Cancer J Clin 67: 7-30.

SOUZA KCB ET AL. 2019. Identification of Cell-Free Circulating MicroRNAs for the Detection of Early Breast Cancer and Molecular Subtyping. J Oncol 2019: 8393769.

TAKAHASHI RU, MIYAZAKI H \& OCHIYA T. 2015. The Roles of MicroRNAs in Breast Cancer. Cancers (Basel) 7: 598-616.

TORRE LA, BRAY F, SIEGEL RL, FERLAY J, LORTET-TIEULENT J \& JEMAL A. 2015. Global cancer statistics, 2012. CA Cancer J Clin 65: 87-108. 
WEIGELT B, GEYER FC \& REIS-FILHO JS. 2010. Histological types of breast cancer: how special are they? Mol Oncol 4: $192-208$.

YUAN Z ET AL. 2017. Dynamic plasma microRNAs are biomarkers for prognosis and early detection of recurrence in colorectal cancer. Br J Cancer 117: 1202-1210.

ZHANG R, GUO Y, MA Z, MA G, XUE Q, LI F \& LIU L. 2017. Long noncoding RNA PTENP1 functions as a ceRNA to modulate PTEN level by decoying miR-106b and miR-93 in gastric cancer. Oncotarget 8: 26079-26089.

\section{SUPPLEMENTARY MATERIAL}

Figure S1. Relative expression of miR-1273g-3p and target gene PTEN.

\section{How to cite}

GUO H, ZENG X, LI H, GUO Y, WANG T, GUO H, ZHU G, WANG L, ZHOU H, LIU K, CHEN X, WANG H, ZHAO X, SU H \& LI Y. 2020. Plasma miR-1273g-3p acts as a potential biomarker for early Breast Ductal Cancer diagnosis. An Acad Bras Cienc 92: e20181203. DOI. 10.1590/0001-3765202020181203.

Manuscript received on November 14, 2018;

accepted for publication on November 12, 2019

HUAN GUO ${ }^{1,2, *}$

https://orcid.org/0000-0003-1580-5912

\section{XIANGTING ZENG ${ }^{3, *}$}

https://orcid.org/0000-0003-4967-9432

\section{HAINING LI ${ }^{2}$}

https://orcid.org/0000-0001-7743-0306

\section{YANXIANG GUO ${ }^{2}$}

https://orcid.org/0000-0002-9025-8528

\section{TAO WANG ${ }^{2}$}

https://orcid.org/0000-0001-9892-812X

\section{HONGYUN GUO ${ }^{2}$}

https://orcid.org/0000-0003-1816-7792

\section{GONGJIAN ZHU ${ }^{2}$}

https://orcid.org/0000-0001-5298-9699

\section{LAN WANG ${ }^{2}$}

https://orcid.org/0000-0003-0437-3974

\section{HAIHONG ZHOU ${ }^{2}$}

https://orcid.org/0000-0002-5128-9399

\section{KEDAN LIU ${ }^{2}$}

https://orcid.org/0000-0003-2228-9530

\section{XIAOYI CHEN ${ }^{2}$}

https://orcid.org/0000-0002-3950-1019

\section{HAITAO WANG ${ }^{2}$}

https://orcid.org/0000-0001-7179-1557

\section{XINKE ZHAO}

https://orcid.org/0000-0002-3460-7279

\section{HAIXIANG SU ${ }^{2,4}$}

https://orcid.org/0000-0002-1654-928X

\section{YINGDONG LI ${ }^{1,4}$}

https://orcid.org/0000-0002-8994-6788

${ }^{1}$ School of Basic Medical Sciences, Lanzhou University, Lanzhou, Gansu, People's Republic of China

${ }^{2}$ Gansu Provincial Cancer Hospital, Gansu

Provincial Academic Institute for Medical Sciences,

Lanzhou, Gansu, People's Republic of China

${ }^{3}$ Department of general surgery, Lanzhou University Second Hospital, Lanzhou, Gansu, People's Republic of China ${ }^{4}$ Gansu University of Chinese Medicine, Lanzhou,

Gansu, People's Republic of China

Correspondence to: Yingdong Li, Haixiang Su

E-mail: liyingdong2014@163.com, haixiang01@yahoo.com

*Equal contribution

\section{Author contributions}

Huan Guo, Xiangting Zeng, Haining Li, Yanxiang Guo, Tao Wang, Hongyun Guo performed the experiments. Gongjian Zhu, Lan Wang, Haihong Zhou provided and cultured breast cancer cells. Huan Guo, Xiangting Zeng, Kedan Liu, Xiaoyi Chen, Haitao Wang, Xinke Zhao statistics data and drafted the manuscript. Huan Guo, Kedan Liu, Yingdong Li and Haixiang Su reviewed and edited the manuscript. All authors participated in revising it critically for important intellectual content. All authors read and approved the manuscript.

(cc) BY 